the hospital is deployed fully or by separate modules. In two surgical modules, medical aid was rendered to about 500 wounded persons in the region of the Chechenskaya Republic.

The established structure and organization of the Russian disaster medicine service creates favorable conditions to achieve a new, higher scientific and practical level of rendering medical aid during the recovery from emergency situations.

\section{9. \\ Advisory Computer System for the Medical Evacuation Support after Chemical Accidents}

K.B. Guigov, MD, PhD, Asst. Prof. A. Galabova

Military Medical Academy, Sofia, Bulgaria

When large industrial accidents with chemical toxicological agents happen, many medical problems appear as follows: 1) mass one-moment losses; 2) different types and degrees of damage; 3) difficult geographic territories; 4) nonidentified at the beginning chemical agents; and 5 ) fast changes in the chemical situation. All these factors make the needed medical evacuation support very difficult.

To optimize the functions of the medical personnel and means activities, we had the task to develop an advisory computer system. The system consists of three combined subsystems: 1) data base; 2) advisory subsystem; and 3) graphic imaging of the concrete situation. The data base has some obligatory information necessary for decision-making: 1) dislocation of the industrial facilities all over the country; 2) the type, quantity, and characteristics of the industrial toxicological agents; 3) some meteorological data; 4) the density of the population; 5) the nearby health facilities; 6) some normative for the medical evacuation support; 7) the mechanisms and roads used for transportation and evacuation, etc. The system is open and permits corrections of the saved information to be done with the new input. As forecasting for the chemical situation changes, for the needed medical personnel and means (according to the number of the damaged), for the choice of the roads for evacuation toward suitable health facilities, for the additional personnel and means is done. Even if only one of the input data items changes, the system reacts immediately. The graphic images of the real situation provide help for the right decision-making, and for its documentation. Our positive experience makes us recommend some advisory computer systems to be used obligatory in the events of chemical accidents to better the needed medical support.

\section{0.}

\section{On the Usage of Specialized Military Medical Personnel and Means}

\author{
K.B. Guigov, $M D, P h D$ \\ Military Medical Academy, Sofia, Bulgaria
}

A problems associated with the provision of medical care to the persons damaged in natural and human-made disasters is that the circumstances are too close to those that the Military Medical Service (MMS) meets in war-time situations. Furthermore, the mass one-moment losses, the severe pathology, and the lack of medical personnel and means call for the MMS to be included in the responses, as already occurs in many countries. The MMS has organized a definitive medical strategies, has established an organizational structure, has prepared for emergency response, and has trained highly qualified personnel. This is why we think MMS ought to be included as a constant not only at "certain stages," but during the entire national system of activities in the event of extreme situations.

With this in mind, we have estimated the capabilities of the military medical personnel and means all over the country, their territorial distribution, capacity and training, and particularly of those located near facilities at risk. A special Military Medical Detachment for Emergency Response (MMDER) was established on the functional-module principle. The organization, manner of acting, personnel, and supplies were developed as a result of scientific research and examination of simulated situations. The personnel pass a special, full-volume training program. The possibilities of the detachment extend with each of the stages, starting at the 15 th minute from the beginning of the disaster. As the detachment is constructed on the module principle, the needed emergency medical units are developed, together with it.

The results obtained make us recommend the action of including of the military medical personnel and means in the liquidation of the consequences in natural and human-made disasters, and in this way the military medical assets help the civil ones in the event of disasters.

\section{8.}

\section{Industrial Disputes as Disasters: Experiences at Woden Valley Hospital}

Dr.J.V. Hodge

Woden Valley Hospital, Woden, Australia

At midnight on 20 November 1993, services provided by VMOs at Woden Valley Hospital in the ACT, were withdrawn as a result of an industrial dispute. From that point in time, services in surgery, anesthetics, pediatrics, and obstetrics were withdrawn, with the exception of some major life-saving surgery which the VMOs still agreed to perform. Over the next five weeks, some 210 patients were transferred to interstate hospitals for care.

This represented a major disaster for the ACT, and although the hospital or ACT Medplans were not activated, components of these plans were utilized, and valuable lessons learned in revising the existing Medplan.

On Friday, 18 November 1993, the annual Canberra Airport Disaster exercise was held, with 26 seriously injured casualties being evacuated to Woden Valley Hospital, the main trauma receiving hospital in the ACT and South Eastern NSW. The hospital's external disaster plan was activated, and these casualties were triaged and managed expeditiously. At midnight on Saturday, 20 November 1993, all VMO services were withdrawn from both Woden Valley and Calvary hospitals, with only lim- 